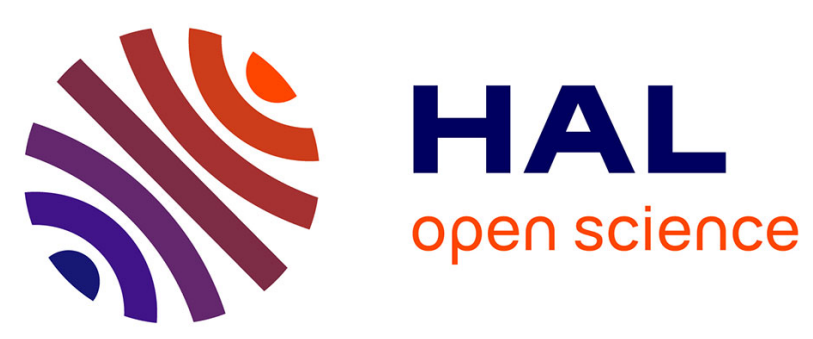

\title{
EXAFS and Mössbauer Study of the Crystallization of Fe91Zr9 Metallic Glass
}

P. Gorria, I. Orue, M. Fdez-Gubieda, L. Fernández Barquín, J. Barandiarán

\section{To cite this version:}

P. Gorria, I. Orue, M. Fdez-Gubieda, L. Fernández Barquín, J. Barandiarán. EXAFS and Mössbauer Study of the Crystallization of Fe91Zr9 Metallic Glass. Journal de Physique IV Proceedings, 1997, 7 (C2), pp.C2-1125-C2-1126. 10.1051/jp4:19972155 . jpa-00255218

\section{HAL Id: jpa-00255218 https://hal.science/jpa-00255218}

Submitted on 1 Jan 1997

HAL is a multi-disciplinary open access archive for the deposit and dissemination of scientific research documents, whether they are published or not. The documents may come from teaching and research institutions in France or abroad, or from public or private research centers.
L'archive ouverte pluridisciplinaire HAL, est destinée au dépôt et à la diffusion de documents scientifiques de niveau recherche, publiés ou non, émanant des établissements d'enseignement et de recherche français ou étrangers, des laboratoires publics ou privés. 


\title{
EXAFS and Mössbauer Study of the Crystallization of $\mathrm{Fe}_{91} \mathrm{Zr}_{9}$ Metallic Glass
}

\author{
P. Gorria, I. Orue, M.L. Fdez-Gubieda, L. Fernández Barquín* and J.M. Barandiarán \\ Departamento de Electricidad y Electrónica, Universidad del País Vasco, Apartado 644, \\ 48080 Bilbao, Spain \\ * CITIMAC (Materiales), F. Ciencias, Universidad de Cantabria, 39005 Santander, Spain
}

\begin{abstract}
The crystallization process of the $\mathrm{Fe}_{91} \mathrm{Zr}_{9}$ amorphous alloy has been followed by means of two experimental techniques, EXAFS and Mössbauer spectroscopy. X-ray absorption spectra on Fe K-edge and Mössbauer spectra of six samples with different degrees of crystallization have been measured at room temperature in order to obtain information about the structural changes that take place. From the beginning of the crystallization process it is clearly seen that a crystalline phase with a bcc-type structure appears. From the obtained data we can conclude that this phase is nearly pure bcc-Fe, with small amount of impurities in its structure.
\end{abstract}

\section{INTRODUCTION}

In recent years $\mathrm{Fe}_{100-\mathrm{x}} \mathrm{Zr}_{\mathrm{x}}$ Fe-rich metallic glasses $(7 \leq \mathrm{x} \leq 14)$, have been attracted considerably attention because their striking magnetic properties [1, 2]. It has been observed that in this composition range the addition of 1 at.\% of $\mathrm{Zr}$ increases the Curie temperature in $20 \mathrm{~K}$ [3]. On the other hand, there are not many works in the literature related with the crystallization of these alloys [4], however, the changes in behaviour that could occur on the magnetic properties due to the structural evolution during the crystallization process is actually subject of discussion. In the present work, we present a preliminary study of the structural evolution of the $\mathrm{Fe}_{91} \mathrm{Zr}_{9}$ sample during the first steps of the crystallization process. X-ray absorption fine structure, EXAFS, and Mössbauer spectroscopy are ideal experimental techniques to perform this study.

\section{EXPERIMENTAL}

A sample of nominal composition $F_{g_{1}} \mathrm{Z}_{r 9}$ was prepared by the melt spinning method under Ar atmosphere with cross section of about $2 \mathrm{~mm} \times 20 \mu \mathrm{m}$. The amorphous state of the as quenched sample was checked by X-ray diffraction. In order to obtain a set of samples with different degrees of crystallization, six strips of the same sample were annealed during one hour at 623 , $673,698,723,748$ and $773 \mathrm{~K}$ in a conventional furnace under Ar atmosphere. In the following we shall call the samples $\mathrm{FeZr} / \mathrm{aq}, \mathrm{FeZr} / 623, \mathrm{FeZr} / 673, \mathrm{FeZr} / 698, \mathrm{FeZr} / 723, \mathrm{FeZr} / 748$ and $\mathrm{FeZr} / 773$ respectively.

Room temperature X-ray absorption spectra have been recorded on Fe K-edge at 7.1 station at Daresbury Laboratory (U.K.) using a Si(111) channel monochromator and $50 \%$ of harmonic rejection. The storage ring was typically running at 2 $\mathrm{GeV}$ and $150 \mathrm{~mA} .{ }^{57} \mathrm{Fe}$ Mössbauer transmission spectra of the samples have been recorded at room temperature in a conventional constant acceleration spectrometer using a ${ }^{57} \mathrm{Co}$ - Rh source. A $20 \mu \mathrm{m}$ thick $\alpha$-Fe foil has been used also to compare the results.

\section{DATA ANALYSIS AND RESULTS}

The absorption spectra have been analized following standard procedures [5]. The average absorption above the edge was fitted in the $k$ range between 2 and $12 \AA^{-1}$ with a smooth spline formed by three cubic polynomials to simulate the atomic cross section. The origin of the $k$ scale was taken at the inflection point of the absorption edge. The amplitude of the EXAFS oscillations, $\chi(k)$, decreases from the $\mathrm{FeZr} / \mathrm{aq}$ sample to the $\mathrm{FeZr} / 623$ and increases again for the $\mathrm{FeZr} / 673$ sample. In the rest of the samples the amplitude increases as the crystalline fraction does. The Fourier transforms of the $\chi(k)$ functions, $\Phi(R)$, presented in fig. 1 (right), have been performed using a $k^{3}$ weight and a Hanning window function in the $2-12 \AA^{-1} k$ range. In the samples annealed at temperatures below $773 \mathrm{~K}$, the crystalline fraction increases very slowly in the samples, hence, the change in shape of the Fourier transforms is not notorious. Furthermore, in the case of the FeZr/773 sample the percentage of crystalline fraction is clearly higher, and the shape of the Fourier transform, including the position of the mean peak, has changed towards the corresponding to the bcc-Fe, (fig. 1 right).

The fitting of the Mössbauer spectra has been performekfwith the NORMOS program, developed by Brand et al. [6], a program which allows a simultaneous fit of several crystalline spectra and a possible amorphous phase characterized by a distribution of hyperfine fields $\left(\mathrm{BHF}_{\mathrm{HF}}\right)$. In fig. 1 (left) the Mössbauer spectra of the samples are represented. All the samples show a typical doublet corresponding to the Quadrupole Splitting of a paramagnetic compound. However, in all the spectra corresponding to the annealed samples the six peaks characteristic of a ferromagnetic phase appear. The hyperfine parameters of 
this ferromagnetic phase correspond to the bcc Fe ones, with slight differences in the value of the $\mathbf{B}_{H F}$. These values differs no more than 0.5 Tesla from the value obtained for the bcc Fe foil ( 33 Tesla) and evolve towards this value as the crystallization goes on. It is also clear, as in the Fourier transforms, that the amount of crystalline bcc Fe is quite low for the samples annealed below $773 \mathrm{~K}$.
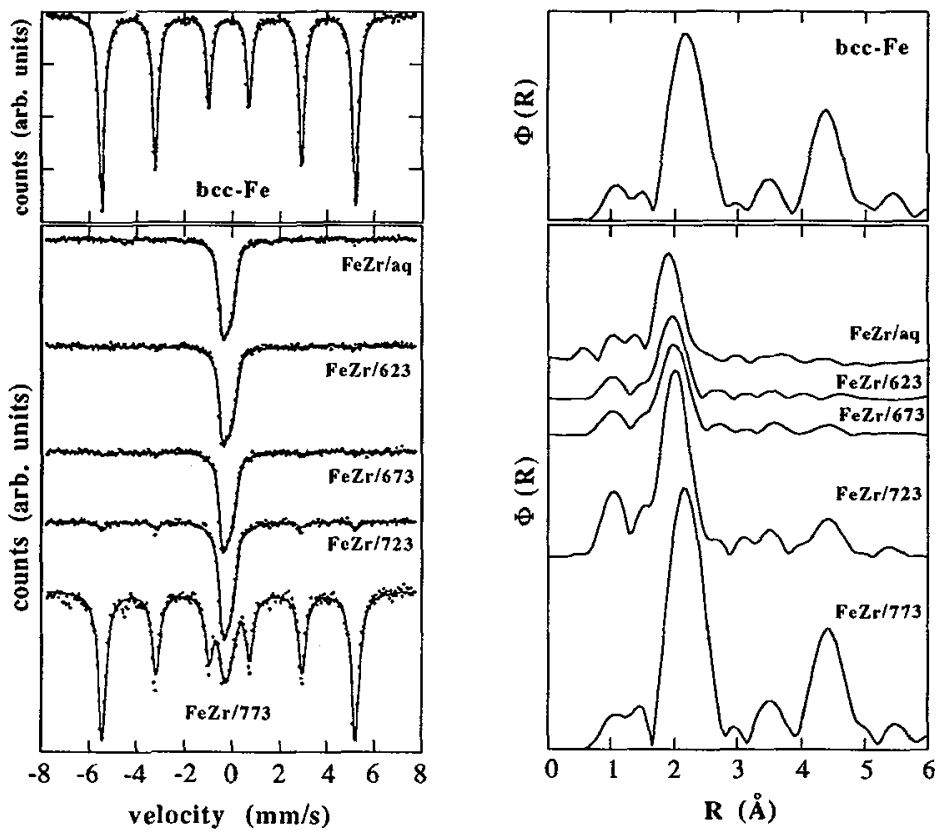

Figure 1: Left part, Mössbauer spectra of some of the studied samples compared with the bec-Fe spectrum. Right part, Fourier transforms of the same samples obtained from EXAFS spectra.

\section{DISCUSSION AND CONCLUSIONS}

In this preliminary study of the crystallization of an Fe-rich FeZr metallic glass, it is clearly shown that the crystallization process has begun at rather low annealing temperatures $(623 \mathrm{~K})$, but for temperatures below $773 \mathrm{~K}$ the amount of crystalline phase is very low $(\approx 3 \%$ in the $\mathrm{FeZr} / 623$ sample and $\approx 10 \%$ in $\mathrm{FeZr} / 748$ sample). The slight differences observed in the hyperfine parameters of this partially crystallized samples, respect to the bcc Fe ones, are probably due to the small size of the crystals (about $20 \mathrm{~nm}$ ). The large number of Fe atoms in the surface of the nanocrystals, in contact with the paramagnetic remaining amorphous phase, feel lower exchange coupling leading to a decrease in the value of the $\mathbf{B}_{\mathrm{HF}}$. The evolution of the structure in the studied samples changes drastically in the case of the FeZr/773 sample. The amount of crystalline phase reaches $\approx 80 \%$ and the size of the crystals is above $0.1 \mu \mathrm{m}$, leading to nearly the same structure and hyperfine values than the policrystaline bcc Fe foil corresponding ones. Magnetic measurements are needed to elucidate more accurately the changes occurring during the crystallization of these compounds.

\section{Acknowledgements}

We thank Daresbury Laboratory for Synchrotron measurements facility and P.U.L.S. group at Frascati Laboratory for providing us EXAFS programs. P.G. and I.O, want to thank Basque Government for financial support under a F.P.I. grant.

\section{References}

[1] Hiroyoshi H. and Fukamichi K., J. Appl. Phys. 53 (1982) 2226.

[2] Kaul S.N., Siruguri V. and Chandra G., Phys. Rev. B 45 (1992) 12343.

[3] Ryan D.H., D. Coey J.M., Batalla E., Altounian Z. and Ström-Olsen J.O., Phys. Rev, B 35 (1987) 8630.

[4] Z. Altounian, E. Batalla and J.O. Strom-Olsen, J. Appl. Phys. 59 (1986) 2364.

[5] Lengeler B. and Eisenberger P., Phys. Rev. B 21 (1980) 4507.

[6] Brand R.A., Lauer J., Herlach D.M., J. Phys. F: Met. Phys. 14 (1984) 555. 